\title{
The Knockout Punch for HER2 Positive Breast Cancer: Addition of an ADAM10 Inhibitor to the Combination Therapy of Trastuzamab and Lapatinib
}

\author{
Marcia L. Moss
}

Biozyme Inc., Apex, North Carolina, USA

Corresponding author: Moss ML, BioZyme Inc., Apex, North Carolina, USA, E-mail: moss0610@yahoo.com

Rec date: March 25, 2016; Acc date: June 23, 2016; Pub date: June 27, 2016

Copyright: (C) 2016 Moss ML. This is an open-access article distributed under the terms of the Creative Commons Attribution License, which permits unrestricted use, distribution, and reproduction in any medium, provided the original author and source are credited.

Citation: Moss ML (2016) The Knockout Punch for HER2 Positive Breast Cancer: Addition of an ADAM10 Inhibitor to the Combination Therapy of Trastuzamab and Lapatinib. Mol Enzyme Drug Targets 2: 12.

\section{Abstract}

The most popular drugs for treating HER2 positive breast cancer are Trastuzumab or lapatinib. Clinical trials in recent years have begun where the two drugs are now being used in combination. Some of the trial results appear to be promising and the combination therapy could provide a new way in which to combat resistance to therapies and improve disease free survival compared to when either drug is used alone. This article describes the benefit of targeting HER2 positive breast cancer with multiple therapies and proposes a novel way in which to treat the disease; to add an ADAM10 inhibitor to the Trastuzumab and lapatinib combination.

\section{Introduction}

Approximately $20-30 \%$ of all breast cancer cases are HER2 positive [1]. HER2 or human epidermal growth factor 2 , is a receptor expressed on the cell surface of breast cells and in normal situations is important for proper maintenance and cell growth [2]. However, in breast cancer, HER2 amounts are amplified so that multiple copies of the growth factor are expressed [3-5]. Increased expression makes the breast cells grow and divide in an abnormal way [2].

Currently, there are very specific treatments for HER2 positive breast cancer. Trastuzumab, or Herceptin is an approved drug developed by Genetech that targets the HER2 protein [6]. Trastuzumab is an antibody that works by binding to the HER2 on the cell surface, and preventing the HER2 from sending signals for cell growth $[7,8]$. Binding of Trastuzumab to the HER2 also targets the cell for destruction by the immune system [8]

Lapatinib is also an approved drug for HER2 positive breast cancer but it targets the HER2 in a very different way than Trastuzumab $[9,10]$. HER2 is a receptor on the cell surface but it is also is a kinase. The kinase activity is necessary in order for the HER2 to send signals inside and between cells $[11,12]$. Lapatinib not only targets the HER2 kinase, but also inhibits epidermal growth factor receptor (EGFR) kinase [13]. EGFR is also another receptor on breast cancer cells that is often dysregulated [14].

These two drugs have been used as single agents to target HER2 breast cancer. However, recently, the two, Trastuzumab, and lapatinib have been used in combination, and while there have been some disappointments, many of the results are promising. Initially, in phase III study EGF104900, women, who had metastatic breast cancer that had been receiving Trastuzumab therapy and were HER2 positive, were randomly assigned to receive lapatinib alone, or lapatinib plus Trastuzumab. With the combination of drugs, there was a better outcome in both progression free and overall survival $[15,16]$, indicating that metastatic HER2 positive breast cancer may be treated with non-cytotoxic agents.

With these promising results, the combination of lapatinib and Trastuzumab was also tested in patients with early stage HER2 positive breast cancer and compared to either agent alone in the other clinical trials. Women who had previous therapies, and were also treated co-currently with cytotoxic agents, before and after surgery, showed no statistically significant difference for any of the treatment groups [17] in that the pathological complete response ( $P C R)$, meaning that no active cancer cells had been found, was the same. However, in two other trials, women who had early stage HER2 positive breast cancer who had no previous treatments, were given Trastuzumab, lapatinib, or the combination of drugs followed by cytotoxic regimens. The pCR rate was significantly higher in the group treated $(51.3 \%)$ with dual inhibition as compared to Trastuzumab alone (29.5\%) and there was no significant difference in PCR between the lapatinib and the Trastuzumab groups $[18,19]$. In more recent study, which is ongoing, event free survival or overall survival, unfortunately, did not differ between the treatment groups. The lack of finding a significant difference in the overall survival and event free survival was attributed to a high response rate. However, the number of patients obtaining a $\mathrm{pCR}$ did increase in the group receiving the combination therapy, and those that did have a pCR, had longer event-free and overall survival [19].

The holy grail for cancer therapy is to provide patients with non-cytotoxic agents that cure their disease. Toward this aim, women with stage 2 HER2 positive breast cancer were divided 
into two groups: the first group received Trastuzumab alone; the second group received the dual treatment of Trastuzumab and lapatinib [20]. Biopsies of the tumors were performed before and after treatment and the women were categorized as either having a $\mathrm{PCR}$ or minimal residual disease (MRD) if the tumor was less than $5 \mathrm{~mm}$ in diameter. After only 11 days, many women saw shrinkage of their tumors. Women who received the combination had an $11 \%$ pCR and 17\% MRD. However, women who received Trastuzumab alone, had $0 \%$ pCR and only a 3\% MRD [20]. All of these findings, taken together, indicate that it may be possible to treat HER2 positive breast cancer patients who have early or late stage detection, with a combination therapy that doesn't have many side effects.

One of the main obstacles to Trastuzumab therapy for HER2 positive breast cancer, is that the cancer often becomes refractory to treatment $[21,22]$. In order for HER2 to function, both under normal and pathological conditions, it must be tethered to the cell membrane and reside on the cell surface. However, in cancer cells resistant to Trastuzumab, the HER2 receptor is released from the membrane so that it no longer is present on the cell surface [23]. The process by which it is released from the membrane is called proteolysis. In proteolysis, enzymes that physically cut other proteins at specific sites, are used to cleave and release receptors such as HER2. Many of the enzymes that cleave other proteins from the cell surface are members of the ADAM or a disintegrin and metalloproteinase family [24-26].

ADAM10 is a member of the ADAM family, and one of its jobs is to cleave HER2 from the cell surface [27]. In many types of cancer, ADAM10 levels are increased, and this was found to be the case in breast cancers resistant to Trastuzumab therapy [28]. ADAM10 processes many proteins from the cell surface, including members of the EGF ligand family [24,29-33]. Therefore, researchers are actively pursuing drugs that will inhibit ADAM10 [34-36].

There are currently four known therapeutic agents that have targeted ADAM10: prodomain of ADAM10 [37]; GI254023 [38]; INCB3619; and INCB7839 [39-43]. The first, generated by Biozyme, Inc, is a protein therapeutic that is the only known selective inhibitor of ADAM10 [37]. ADAM family members are typically expressed as precursor proteins in an inactive state [44]. ADAM10 is initially made with the N-terminus of the protein consisting of a region called the prodomain. However, within the cell, the prodomain is proteolytically removed by other proteolytic enzymes, and the ADAM10 becomes active and resides on the cell surface where it cleaves receptors, cytokines, and growth factors from the membrane [45]. When researchers prepared the isolated prodomain of ADAM10, they determined that it was a very specific inhibitor of ADAM10, and when added to cells, it could prevent the release of receptors such as HER2 and members of the EGFR family $[37,46]$. Furthermore, it could prevent certain tumor cell lines from growing [34].

G1254023, a Glaxo Smith Kline inhibitor, in contrast, is a small molecule and while it potently inhibits ADAM10, it also targets members of a closely related family called the matrix metalloproteinases (MMP) [38]. GI254023 has been used extensively to demonstrate that many proteolytic events are carried out by ADAM10 [47-49]. It has also been used in tumor cell lines to demonstrate that it can reduce growth rates and invasiveness of the cells [50]. There is currently no published data on whether the prodomain of ADAM10, or GI254023 have been tested in animal models.

INCB3619 and INCB7839, discovered by Incyte, are not only ADAM10, but also ADAM17 inhibitors. ADAM17 is another member of the ADAM family that also releases receptors, cytokines and growth factors from the cell surface $[24,51,52,33]$. INCB3619 was the first to be tested in a preclinical cancer model for cancer. In a non small cell lung cancer tumor animal model, it had efficacy when used alone or in combination with paclitaxel [39]. Subsequently, it was used alone and in combination with gefitinib or paclitaxel in breast tumor animal models where it showed promise and it had no overt toxic side effects $[40,41]$.

In a preclinical animal model, the combination of INCB7839 with Trastuzumab was more beneficial than either agent alone [53]. In addition, INCB7839 was also tested either alone or in combination with lapatinib in animal models [42]. Again, the combination therapy was better than single agents. There are several rationales as to why an ADAM10 inhibitor proves to be synergistic with Trastuzumab or lapatinib therapies. Much of the regulated signaling in cells is done by cell surface receptors such as HER2. Once it is shed, it is no longer available on the cell surface for Trastuzumab or lapatinib to bind. This phenomenon, where cell surface receptors are shed, so that antibody type therapeutic agents can no longer bind to the active, membrane bound form, could be a common way in which resistance is acquired. Furthermore, once shedding occurs, a constitutively, unregulated, active form of the kinase is then generated on the cell surface which causes the cancer to become more aggressive. In addition, lapatinib also inhibits the EGFR kinase. ADAM10 not only inhibits HER2, but also EGFR signaling events by preventing release of ligands of the EGF family. Thus, the combination of lapatinib and and ADAM10 inhibitor complement each other by acting on different mechanisms of EGFR signaling.

Recently, Ebbing et al. [54] showed that in esophageal cancer tumor cell lines, HER3 or heregulin, is processed by ADAM10 and that this process confers resistance to Trastuzumab. Blockage of ADAM10 or HER3 restores the ability of Trastuzumab to inhibit tumor proliferation using in vitro and in vivo models. Many pharmaceutical companies are now making antibodies that target HER3 in the hope that they can be used to overcome resistance to therapies such as Trastuzumab and other drugs [55]. Trastuzumab resistance is a complex process, but for HER2 positive breast cancer, where ADAM10 is a key player, an inhibitor of this enzyme will not only target pathways driven by multiple growth factors, but also build up HER2 on the cell surface, so that therapies like Trastuzumab and lapatinib can be more effective.

The only published clinical trial on the use of an ADAM10 inhibitor has been with INCB7839. In a phase I/IIA clinical trial with HER2 positive metastatic breast cancer patients, 
INCB7839 had very few adverse events (deep vein thrombosis developed in a small but statistically significant number of patients) [43]. In addition, the combination of INC7839 with Trastuzumab, resulted in a reduction in a tumor biomarker level called p95. p95 is a fragment of HER2 that is left in the cell membrane when HER2 is cleaved from the cell surface and it is found in tumors with a poor clinical response rate likely because a constitutively active kinase is generated [43]. Therefore, less of the p95 fragment, suggests that the response rate to Trastuzumab would be higher if INC7839 were given. In this same study, other biomarker levels such as soluble EGF ligand family members were reduced with INCB7839 treatment.

Thus, with the recent encouraging findings from Glaxo SmithKline using the combination therapy with Trastuzumab and lapatinib, the time has come to develop and/or progress inhibitors of ADAM10, in the hope that a triple combination therapy can be used to treat HER2 positive breast cancer. ADAM10 inhibitors have been proven to be very safe, with no side effects that were seen with previous inhibitors of the ADAM and MMP family members [56]. Furthermore, an ADAM10/ADAM17 inhibitor was effective in treating tumors in preclinical models when used in combination with Trastuzumab or lapatinib and in the clinic, INC7839 synergized with Trastuzumab to reduce biomarker levels in HER 2 positive breast cancer patients with metastatic disease. Since one of the major ways cancer cells avoid resistance could be through shedding of cell surface proteins, it is expected that addition of an ADAM10 inhibitor to therapies with Trastuzumab and lapatinib, could greatly increase survival rate of HER2 positive breast cancer patients, without the multitude of side effects that are common with cytotoxic agents.

\section{References}

1. Slamon DJ, Godolphin W, Jones LA, Holt JA, Wong SG, et al. (1989) Studies of the HER-2/neu proto-oncogene in human breast and ovarian cancer. Science 244: 707-712.

2. Rubin I, Yarden $Y$ (2001) The basic biology of HER2. Ann Oncol 12: S3-8.

3. Ullrich A, Coussens L, Hayflick JS, Dull TJ, Gray A, et al. (1984) Human epidermal growth factor receptor cdna sequence and aberrant expression of the amplified gene in a431 epidermoid carcinoma cells. Nature 309: 418-425.

4. Slamon DJ, Clark GM, Wong SG, Levin WJ, Ullrich A, et al. (1987) Human breast cancer: correlation of relapse and survival with amplification of the HER-2/neu oncogene. Science 235: 177-182.

5. King CR, Kraus MH, Aaronson SA (1985) Amplification of a novel v-erbB-related gene in a human mammary carcinoma. Science 229: 974-976.

6. D. Slamon (2000) Herceptin: Increasing survival in metastatic breast cancer. European journal of oncology nursing 4: 24-29.

7. Emens LA, Davidson NE (2004) Trastuzumab in breast cancer. Oncology 18: 1117-1128.

8. Baselga J, Albanell J (2001) Mechanism of action of anti-HER2 monoclonal antibodies. Ann Oncol 12: S35-41.
9. Kim HP, Yoon YK, Kim JW, Han SW, Hur HS, et al. (2009) Lapatinib, a dual egfr and her2 tyrosine kinase inhibitor, downregulates thymidylate synthase by inhibiting the nuclear translocation of egfr and her2. PloS one 4: e5933.

10. Scaltriti M, Verma C, Guzman M, Jimenez J, Parra JL, et al. (2009) Lapatinib, a her2 tyrosine kinase inhibitor, induces stabilization and accumulation of her2 and potentiates trastuzumabdependent cell cytotoxicity. Oncogene 28: 803-814.

11. Stern DF (2000) Tyrosine kinase signalling in breast cancer: ErbB family receptor tyrosine kinases. Breast Cancer Res 2: 176-183.

12. M. A. Alaoui-Jamali (2006) Protein tyrosine kinase signaling diversity and susceptibility to targeted kinase inhibitors. Biomedecine \& pharmacotherapie 60: 629-632.

13. Johnston SR, Leary A (2006) Lapatinib: a novel EGFR/HER2 tyrosine kinase inhibitor for cancer. Drugs Today (Barc) 42: 441-453.

14. Masuda H, Zhang D, Bartholomeusz C, Doihara H, Hortobagyi $\mathrm{GN}$, et al. (2012) Role of epidermal growth factor receptor in breast cancer. Breast cancer research and treatment 136: 331-345.

15. Blackwell KL, Burstein HJ, Storniolo AM, Rugo H, Sledge G, et al. (2010) Randomized study of lapatinib alone or in combination with trastuzumab in women with erbb2-positive, trastuzumabrefractory metastatic breast cancer. J clin oncol 28: 1124-1130.

16. Blackwell KL, Burstein HJ, Storniolo AM, Rugo HS, Sledge G, et al. (2012) Overall survival benefit with lapatinib in combination with trastuzumab for patients with human epidermal growth factor receptor 2-positive metastatic breast cancer: Final results from the EGF104900 study. J clin oncol 30: 2585-2592.

17. Robidoux A, Tang G, Rastogi P, Geyer CE, Azar CA, et al. (2013) Lapatinib as a component of neoadjuvant therapy for HER2positive operable breast cancer (NSABP protocol b-41): An openlabel, randomised phase 3 trial. Lancet Oncol 14: 1183-1192.

18. Baselga J, Bradbury I, Eidtmann H, Di Cosimo S, de Azambuja E, et al. (2012) Lapatinib with trastuzumab for HER2-positive early breast cancer (neoALTTO): a randomised, open-label, multicentre, phase 3 trial. Lancet 379: 633-640.

19. de Azambuja E, Holmes AP, Piccart-Gebhart M, Holmes E, Di Cosimo S, et al. (2014) Lapatinib with trastuzumab for HER2positive early breast cancer (neoALTTO): Survival outcomes of a randomised, open-label, multicentre, phase 3 trial and their association with pathological complete response. Lancet Oncol 15: 1137-1146.

20. https://www.theguardian.com/society/2016/mar/10/breastcancer-study-finds-drug-combination-that-gives-astonishingresults

21. Nahta R, Esteva FJ (2006) Herceptin: mechanisms of action and resistance. Cancer Lett 232: 123-138.

22. Vu T, Claret FX (2012) Trastuzumab: updated mechanisms of action and resistance in breast cancer. Front Oncol 2: 62

23. Duffy MJ, Crown J, Mullooly M (2014) ADAM10 and ADAM17: New players in trastuzumab tesistance. Oncotarget 5: 10963-10964.

24. Edwards DR, Handsley MM, Pennington CJ (2008) The ADAM metalloproteinases. Mol Aspects Med 29: 258-289.

25. Murphy G (2008) The ADAMs: signalling scissors in the tumour microenvironment. Nat Rev Cancer 8: 929-941. 
26. Pruessmeyer J, Ludwig A (2009) The good, the bad and the ugly substrates for ADAM10 and ADAM17 in brain pathology, inflammation and cancer. Semin Cell Dev Biol 20: 164-174.

27. Liu PC, Liu X, Li Y, Covington M, Wynn R, et al. (2006) Identification of ADAM10 as a major source of HER2 ectodomain sheddase activity in HER2 overexpressing breast cancer cells. Cancer Biol Ther 5: 657-664.

28. Feldinger K, Generali D, Kramer-Marek G, Gijsen M, Ng TB, et al. (2014) ADAM10 mediates trastuzumab resistance and is correlated with survival in HER2 positive breast cancer. Oncotarget 5: 6633-6646.

29. Yan Y, Shirakabe K, Werb Z (2002) The metalloprotease Kuzbanian (ADAM10) mediates the transactivation of EGF receptor by $G$ protein-coupled receptors. J Cell Biol 158: 221-226.

30. Sahin U, Weskamp G, Kelly K, Zhou HM, Higashiyama S, et al. (2004) Distinct roles for ADAM10 and ADAM17 in ectodomain shedding of six EGFR ligands. J Cell Biol 164: 769-779.

31. Horiuchi K, Le Gall S, Schulte M, Yamaguchi T, Reiss K, et al. (2007) Substrate selectivity of epidermal growth factor-receptor ligand sheddases and their regulation by phorbol esters and calcium influx. Molecular biology of the cell 18: 176-188.

32. Higashiyama S, Nanba D (2005) ADAM-mediated ectodomain shedding of HB-EGF in receptor cross-talk. Biochim Biophys Acta 1751: 110-117.

33. Peschon JJ, Slack JL, Reddy P, Stocking KL, Sunnarborg SW, et al. (1998) An essential role for ectodomain shedding in mammalian development. Science 282: 1281-1284.

34. Crawford HC, Dempsey PJ, Brown G, Adam L, Moss ML (2009) ADAM10 as a therapeutic target for cancer and inflammation. Curr Pharm Des 15: 2288-2299.

35. Moss ML, White JM, Lambert MH, Andrews RC (2001) Tace and other adam proteases as targets for drug discovery. Drug discov Today 6: 417-426.

36. Moss ML, Bartsch JW (2004) Therapeutic benefits from targeting of ADAM family members. Biochemistry 43: 7227-7235.

37. Moss ML, Bomar M, Liu Q, Sage H, Dempsey $P$, et al. (2007) The ADAM10 prodomain is a specific inhibitor of ADAM10 proteolytic activity and inhibits cellular shedding events. J Biol Chem 282: 35712-35721.

38. Ludwig A, Hundhausen C, Lambert MH, Broadway N, Andrews RC, et al. (2005) Metalloproteinase inhibitors for the disintegrinlike metalloproteinases ADAM10 and ADAM17 that differentially block constitutive and phorbol ester-inducible shedding of cell surface molecules. Comb Chem High Throughput Screen 8 : 161-171.

39. Zhou BB, Peyton M, He B, Liu C, Girard L, et al. (2006) Targeting ADAM-mediated ligand cleavage to inhibit HER3 and EGFR pathways in non-small cell lung cancer. Cancer Cell 10: 39-50.

40. Liu X, Fridman JS, Wang Q, Caulder E, Yang G, et al. (2006) Selective inhibition of ADAM metalloproteases blocks HER-2 extracellular domain (ECD) cleavage and potentiates the antitumor effects of trastuzumab. Cancer biol ther 5: 648-656.

41. Fridman JS, Caulder E, Hansbury M, Liu X, Yang G, et al. (2007) Selective inhibition of adam metalloproteases as a novel approach for modulating erbB pathways in cancer. Clini cancer Res 13: 1892-1902.

42. Witters L, Scherle $P$, Friedman S, Fridman J, Caulder E, et al. (2008) Synergistic inhibition with a dual epidermal growth factor receptor/HER-2/NEU tyrosine kinase inhibitor and a disintegrin and metalloprotease inhibitor. Cancer Res 68: 7083-7089.

43. Newton RC, Bradley EC, Levy RS, Doval D, Bondarde S, et al. (2010) Clinical benefit of INCB7839, a potential and selective ADAM inhibitor, in combination with trastuzumab in patients with metastatic HER2-positive breast cancer. J Clin Oncol 28: 7.

44. Becherer JD, Blobel CP (2003) Biochemical properties and functions of membrane-anchored metalloprotease-disintegrin proteins (ADAMS). Curr top dev biol 54: 101-123.

45. Moss ML, Stoeck A, Yan W, Dempsey PJ (2008) ADAM10 as a target for anti-cancer therapy. Curr Pharm Biotechnol 9: 2-8.

46. Moss ML, Powell G, Miller MA, Edwards L, Qi B, et al. (2011) ADAM9 inhibition increases membrane activity of ADAM10 and controls alpha-secretase processing of amyloid precursor protein. The Journal of biological chemistry 286: 40443-40451.

47. Hundhausen C, Misztela D, Berkhout TA, Broadway N, Saftig P, et al. (2003) The disintegrin-like metalloproteinase ADAM10 is involved in constitutive cleavage of CX3CL1 (fractalkine) and regulates CX3CL1-mediated cell-cell adhesion. Blood 102: 1186-1195.

48. Woods NK, Padmanabhan J (2013) Inhibition of amyloid precursor protein processing enhances gemcitabine-mediated cytotoxicity in pancreatic cancer cells. J Biol Chem 288: 30114-30124.

49. Paudel S, Kim YH, Huh MI, Kim SJ, Chang Y, et al. (2013) ADAM10 mediates $\mathrm{n}$-cadherin ectodomain shedding during retinal ganglion cell differentiation in primary cultured retinal cells from the developing chick retina. J Cell Biochem 114: 942-954.

50. Ma S, Xu J, Wang X, Wu QY, Cao J, et al. (2015) Effect of ADAM10 inhibitor GI254023X on proliferation and apoptosis of acute TLymphoblastic leukemia jurkat cells in vitro and its possible mechanisms. Zhongguo Shi Yan Xue Ye Xue Za Zhi 23: 950-955.

51. Moss ML, Jin SL, Milla ME, Bickett DM, Burkhart W, et al. (1997) Cloning of a disintegrin metalloproteinase that processes precursor tumour-necrosis factor-alpha. Nature 385: 733-736.

52. Black RA, Rauch CT, Kozlosky CJ, Peschon JJ, Slack JL, et al. (1997) A metalloproteinase disintegrin that releases tumour-necrosis factor-alpha from cells, Nature 385: 729-733.

53. http://library.corporate-ir.net/library/69/697/69764/items/ 273301/SABCS\%202007\%20-\%20Poster\%206065.pdf

54. Ebbing EA, Medema JP, Damhofer $\mathrm{H}$, et al. (2016) ADAM10mediated release of heregulin confers resistance to trastuzumab by activating HER3. Oncotarget 7: 10243-10254.

55. Aurisicchio L, Marra E, Roscilli G, Mancini R, Ciliberto G (2012) The promise of anti-ErbB3 monoclonals as new cancer therapeutics. Oncotarget 3: 744-758.

56. Moss ML, Sklair-Tavron L, Nudelman R (2008) Drug insight: Tumor necrosis factor-converting enzyme as a pharmaceutical target for rheumatoid arthritis, Nature clinical practice. Rheumatology 4: 300-309. 